THE right of the government of the a panel session "Cybernetics, Mathehost country to an international con- matics and Artificial Intelligence". ference to refuse entry visas to foreign delegates has long been a vexed one. The Tbilisi conference on artificial intelligence (September 2-8) produced an interesting variation on this problem: country to refuse to admit its own and talking with them on nationals.

The problem in this case was that of Jewish refusnik scientists, still living within the Soviet Union but dismissed from their academic posts while awaiting a visa for Israel. Although the Soviet scientific hosts of the conference were quite willing to admit them, the KGB was totally opposed to this and considered their wish to attend as being a "provocation". The international organising committee, however, made strong representations that, should these scientists be refused permission to attend, there would be forceful protests and resulting adverse publicity. Consequently, for fear of a withdrawal by the USA and other Western delegations, and as a result of last minute meetings in Moscow, the authorities decided to permit Dr Aleksandr Lerner to travel from Moscow to attend the conference. He was escorted to Tbilisis by the same KGB officer who had formally told him he could not go and welcomed by the head of the Cybernetics Institute of the Georgian Academy of Sciences, Dr V. V. Chavchanidze, who had himself photographed pinning on Lerner's to Isaeli scientists. No scientists resiconference badge. Although subjected dent in Israel were allowed to attend, veillance throughout the conference, present working in the USA, received strains of potatoes, and that mainstay Lerner was able to circulate freely a promise of a visa far too late for him of agricultural planning of the among the delegates and take part in to attend. Nevertheless, two other Khrushchev era-maize.
Israelis from the USA, Judah Pearl and Meir Weinstein, were permitted to attend, so that the Soviet authorities fulfilled at least the letter of the unofficial working agreement on international conferences-that although individual delegates may be refused entry, no national delegation will be excluded in toto.

- The Presidium of the Supreme Soviet of the USSR has announced that "The Order of Friendship of Nations" has been awarded, individually, to each of the Academies of Science of the Union Republics of the USSR, namely, to the Ukrainian, Byelorussian, U z b e k, Kazakh, Georwian, Azeri, Lithuanian, Moldavian, Latvian, Kirgiz, Tadjik, Armenian, Turkmenian, and Estonian Academies, "for service in the development of Soviet science, economics, and culture, and in the training of highly qualified scientific cadres". One Republic only is not so honoured-the Russian Federated Republic, which has no academy of its own.

- Reconstruction work has began at the highest botanical garden in the world, at Khorog in Tadjikstan. The garden, at a site in the High Pamirs some $2000 \mathrm{~m}$ above sea-level ("above the clouds") is extensively used for field work on the introduction and acclimatisation of plants in extremal conditions. The plants, received on a basis of a regular exchange of seed with 30 Soviet and 36 foreign botanical gardens, therefore include not only and the Hindu Kush, but also more igh-altitude flora from the Himal
There are indications that the new head of the Soviet space establishment, Academician Roald Sagdeyev, has wider interests in space cooperation than costly "spectaculars". Space scientists of the West first made his acquaintance at this $\mathrm{summer}$ ' $\mathrm{m}$ COSPAR Symposium in Bulgaria (COSPAR is shorthand for the ICSU Committee for Space Research, the principal international scientific-as opposed to technological - meeting ground). The impression he made was fresh and favourable: he is youngish, full of ideas, and expresses them in excellent English. This is not quite the image projected by his long-surviving predecessor, Academician Blagdonravov-a loveable octogenarian if ever there was one-who died earlier this year.

Sagdeyev's actual post as head of the USSR Institute of Space Research in Moscow puts him in a key position to monitor international developments at

\section{Plans for space}

from Angela Croome

least in the physical sciences. Soviet development of ideas for experiments must surely have seemed to stagnate since the 1950s; sputniks were becoming not only relatively smaller but stupider. At the COSPAR meeting, Sagdeyev was not only responsive to the idea of international cooperation in certain fields but showed particular interest in getting involved in X-ray astronomy projects.

On the organisational front, the initiative seems to have passed from the USA (at least temporarily). The formation of the European Space Agency (ESA) as a matching body to NASA has thrown into prominence the lack of a learned body in Europe, comparable with the Space Sciences Board of the US National Academy of Sciences, to give informed but inde- 